\title{
Lower limb surgeries under combined femoral and sciatic nerve block at $\mathrm{NMCH}$, Patna, Bihar
}

\author{
Nitin ${ }^{1}$, Prem Shankar Tiwary ${ }^{2 *}$, Ashok Kumar ${ }^{3}$ \\ ${ }^{1}$ Assistant Professor, ${ }^{3}$ Professor \& HOD, Department of Anaesthesiology \& Critical Care, Nalanda Medical College \& Hospital, Patna, Bihar, \\ INDIA. \\ ${ }^{2}$ Assistant Professor, Department of Anaesthesiology, Anugrah Narayan Magadh Medical College \& Hospital, Gaya, Bihar, INDIA. \\ Email: drprem64@gmail.com
}

Abstract Background: Peripheral nerve blocks are gaining popularity for many infraumblical surgeries with the development of new techniques such as ultrasound and peripheral nerve stimulator. It provides stable hemodynamic, better, and prolonged postoperative analgesia. This study was carried out to see the effectiveness of combined femoral and sciatic nerve block with ropivacaine alone and by adding fentanyl. Materials and Methods: The study was carried out on 100 patients scheduled for lower limb surgeries and were randomly divided into two groups of 50 each. In Group A, patients received $20 \mathrm{ml}$ of $0.5 \%$ ropivacaine for femoral nerve block and same dose for sciatic nerve block and in Group B, $25 \mu \mathrm{g}$ fentanyl was added each for femoral nerve and sciatic nerve block along with ropivacaine. All hemodynamic parameters, onset and duration of sensory and motor blocks were noted. The patient characteristics were analyzed using the "Chi-square tests" and the intergroup comparison of the parametric data was carried out using the unpaired $t$-test using software IBM SPSS 17.0. Results: Combined femoral and sciatic nerve block provide longer duration of postoperative analgesia of about 12$13 \mathrm{~h}$. All the above-mentioned parameters were statistically non-significant. Conclusion: Hence in this study, onset and duration of sensory and motor block was comparable in both groups. However postoperative analgesia was prolonged as compared to neuraxial blockade without any hemodynamic instability.

Key Words: Peripheral nerve blocks, regional anesthesia, ropivacaine, sciatic block, sensory block

*Address for Correspondence:

Dr Prem Shankar Tiwary, Assistant Professor, Department of Anaesthesiology, Anugrah Narayan Magadh Medical College \& Hospital,

Gaya, Bihar, INDIA.

Email: drprem64@gmail.com

Received Date: 28/04/2020 Revised Date: 14/05/2020 Accepted Date: 26/05/2020

DOI: https://doi.org/10.26611/10151512

This work is licensed under a Creative Commons Attribution-NonCommercial 4.0 International License. (cc)) EY-NC

\begin{tabular}{|l|l|}
\hline \multicolumn{2}{|c|}{ Access this article online } \\
\hline Quick Response Code: & Website: \\
\hline & www.medpulse.in \\
\cline { 2 - 2 } & \\
\hline
\end{tabular}

\section{INTRODUCTION}

Regional block anesthesia is the best option for life-saving operations where both general and central neuraxial anesthesia are risky, since no fasting, special preparation, or preoperative optimization is required. Furthermore, peripheral nerve blocks provide surgical anesthesia with better cardiorespiratory stability as compared to the central neuraxial blockade which having side effects of hypotension, bradycardia, meningitis, postdural puncture headache, hematoma, neurological deficit, etc. With the development of new techniques such as ultrasound and peripheral nerve stimulator, the scope of anesthesia has shifted from general anesthesia (GA) and central neuraxial blockade for isolated limb surgery to peripheral nerve blocks. One of the most useful but most neglected anesthetic technique is the combination of sciatic and femoral nerve block (3:1) for lower limb surgery. However, the maximum dose of a drug used should be kept in mind as large volumes are used in two blocks. Ropivacaine is a long-acting amide local anesthetic. Being less lipophilic than bupivacaine resulting in less central nervous system toxicity and cardiotoxicity. The addition of adjuvants leads to lowering of drug dose, early onset and with prolonged duration. The purpose of this study was to compare efficacy of $0.5 \%$ ropivacaine alone and $0.5 \%$ ropivacaine with fentanyl in combined femoral and sciatic nerve block with respect to onset and duration of the block as primary aim and duration of analgesia and 
complications associated with it over others traditional methods as a secondary aim.

\section{MATERIAL AND METHODS}

In a prospective, randomized, double-blind study, 100 patients of American Society of Anesthesiologists (ASA) Grades I, II and III in the age group of 18-65 years of either sex scheduled for lower limb surgeries were included. Patient's refusal, morbid obesity, pregnancy, and allergy to the study drug were excluded from the study. Informed written consent of patients was obtained and was randomly divided into two groups of 50 each using sealed envelopes. The technique of combination of femoral and sciatic nerve was given to patient to provide complete surgical anaesthesia around the knee and below the knee. In Group A, patients received $20 \mathrm{ml}$ of $0.5 \%$ ropivacaine for femoral nerve block and $20 \mathrm{ml}$ of $0.5 \%$ ropivacaine for sciatic nerve block and in Group B, patients received $20 \mathrm{ml}$ of $0.5 \%$ ropivacaine plus $25 \mu \mathrm{g}$ fentanyl for femoral nerve block and $20 \mathrm{ml}$ of $0.5 \%$ ropivacaine plus fentanyl $25 \mu \mathrm{g}$ for sciatic nerve block. A day before surgery detailed preanesthetic checkup was done. Visual analog scale (VAS) was explained to the patients to determine the level of analgesia in the postoperative period. It was carried out with a $0-10 \mathrm{~cm}$ line with mark "0" means "no pain" and mark " 10 " means "severe pain." Tablet al.prazolam 0.25 $\mathrm{mg}$ was given on the night before surgery. On the day of operation, multipara monitor was attached and baseline respiratory rate (RR), heart rate (HR), noninvasive blood pressure, peripheral oxygen saturation and electrocardiography were recorded and were monitored at every $5 \mathrm{~min}$ interval until $30 \mathrm{~min}$ of local anesthetic injection and then every $10 \mathrm{~min}$ until $1 \mathrm{~h}$ and then every 15 min until the end of surgery. Oxygen administered via oxygen mask at $6 \mathrm{~L} / \mathrm{min}$. Intravenous (i.v.) line was secured with 18-gauge intracath and injection midazolam $0.04 \mathrm{mg} / \mathrm{kg}$ body weight was given. Patients were preloaded with $10 \mathrm{ml} / \mathrm{kg}$ body weight of Ringer lactate solution over 15-20 min. For femoral nerve block, the patient was kept in supine position with leg extended and the table flattened to maximize operator access to the inguinal region. Under all aseptic precautions, the femoral block was given by inserting 22-gauge needle $1.5-2 \mathrm{~cm}$ lateral to the femoral artery and $1-2 \mathrm{~cm}$ distal to an inguinal ligament in a cephalic direction at $30-45^{\circ}$ angle using nerve stimulator [Figure 1]. The needle was advanced till motor response in the form of dancing patella with the help of nerve stimulator using a current of $2.0 \mathrm{~mA}$. The drug was injected when contractions were elicited at a current of $0.3-0.5 \mathrm{~mA}$. For sciatic nerve block, the patient was placed in lateral decubitus position (operative side up) with the normal leg kept straight and the hip joint of the upper leg in the $40^{\circ}$ of flexion, $20-30^{\circ}$ of adduction and neutral as to rotation [Figure 2]. The knee of the extremity to be blocked was flexed at a $90^{\circ}$ angle, so that posterior superior iliac spine, greater trochanter, and knee come in straight line. Sciatic nerve block was given by inserting a needle at the intersection point of perpendicular from the midpoint of line between greater trochanter to posterior superior iliac spine to line drawn between greater trochanter to sacral hiatus. Needle advanced until contraction in the form of plantar flexion with a peripheral nerve stimulator. Assessment of block and monitoring was carried out by taking time 0 as the time of the completion of the anesthetic injection. Sensory block was assessed as loss of pinprick sensation to a 22-gauge needle for both femoral and sciatic distributions every $5 \mathrm{~min}$ for the first 20 min then every 10 min till complete surgical anesthesia. The onset of sensory block was taken as when patient has no pain (score 2) in the lower limb. Total duration of sensory loss was taken as when patient again started feeling of dull pain (score 1) in the lower limb. Motor blockade was evaluated based on modified Bromage scale as no movement (4), unable to raise the extended leg or bend the knees (3), unable to raise the extended leg, but able to bend the knees (2), able to move the feet, but not able to bend the knees (1), complete leg and foot movement (0) at an interval of $5 \mathrm{~min}$ for the first $20 \mathrm{~min}$ then every 10 min till complete loss of movement occur.

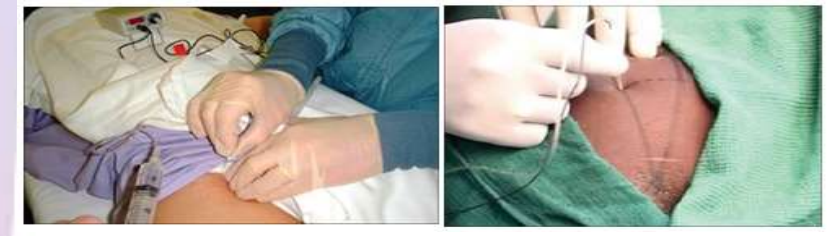

Figure 1: Technique of femoral nerve block; Figure 2: Technique of sciatic nerve block

Onset of motor block was taken as no movement (score 4) and total duration of motor block till resolution of motor block at knee and foot (score 1). Pain score was assessed every 30 min during surgery. In case, patient experienced mild pain (VAS $\leq 3$ ) intraoperative supplementation was given in the form of injection ketamine $0.5 \mathrm{mg} / \mathrm{kg}$ intravenously. This was repeated within 10 min interval to a maximum of 2 times, after which the patient was given GA and were excluded from study. Sedation score using four point scale awake (1), drowsy but responsive to command (2), very drowsy but responsive to pain (3), unresponsive (4) was monitored every 5 min for first 30 min then every $10 \mathrm{~min}$ for $1 \mathrm{~h}$ then 15 min until completion of surgery. Postoperatively patient's sensory, motor block and VAS score was assessed half an hourly for $1 \mathrm{~h}$ then hourly for $8 \mathrm{~h}$ then 2 hourly for $12 \mathrm{~h}$ then 3 hourly for $24 \mathrm{~h}$ after giving block. Rescue analgesia was given in the form of injection diclofenac sodium dose $75 \mathrm{mg} \mathrm{i} / \mathrm{m}$ or injection tramadol $50 \mathrm{mg}$ slow i.v. Time of demand of first rescue 
analgesic was noted. Injection ondansteron i.v. was given for postoperative nausea and vomiting. The patients were monitored for side effects and complications such as intravascular injection, nerve damage, infection, neuropathy. Nerve damage was monitored in the form of any residual weakness in blocked limb. The data from this study was systematically collected, compiled and statistically analyzed using software IBM SPSS 17.0 (SPSS Inc., IBM, Chicago, IL, USA) to draw relevant conclusions. Data was expressed as a mean and standard deviation, number, and percentages. The patient characteristics were analyzed using the "Chi-square tests" and the inter group comparison of the parametric data was carried out using the unpaired $t$-test. The $P$ value was finally determined to evaluate the level of significance. $P<0.05$ was considered significant at $5 \%$ significance level; $P<0.01$ was considered significant at $1 \%$ significance level and $P<0.001$ was considered highly significant.

\section{RESULTS}

This study was carried out on 100 patients divided into two groups of 50 each of age group of 18-65 years with ASA Grades I, II, and III and all patients completed the work in period of $1 \frac{1}{2}$ years, both groups underwent surgeries around knee and below knee with no failure rate and no surgical case cancellation and were comparable with respect to demographic characteristics, hemodynamic parameters, side effects at various time intervals starting from baseline until completion of surgery and mean duration of surgery as shown in Table 1.

Table 1: Demographic variables in Groups A and B

\begin{tabular}{|c|c|c|}
\hline Demographic variables & Group $A(n=50)$ & Group $B(n=50)$ \\
\hline Age distribution (Years) & $39.10 \pm 13.55$ & $36.82 \pm 12.21$ \\
\hline \multicolumn{3}{|l|}{ Sex distribution } \\
\hline Males & 41 & 38 \\
\hline Females & 9 & 12 \\
\hline \multicolumn{3}{|l|}{ ASA Grade } \\
\hline I & 28 & 30 \\
\hline II & 19 & 19 \\
\hline III & 3 & 1 \\
\hline Duration of surgery (min) & $93.36 \pm 15.045$ & $87.37 \pm 19.012$ \\
\hline
\end{tabular}

After administering the study drug, the mean time taken for onset of sensory and motor block and their duration is shown in Table 2.

Table 2: Sensory and motor block characteristics in Groups A and B

\begin{tabular}{|c|c|c|c|}
\hline Parameter & Group $A(n=50)$ & Group $A(n=50)$ & Significance \\
\hline Mean onset time of sensory block (in $\mathrm{min}$ ) & $13.58 \pm 2.604$ & $13: 14 \pm 2.222$ & $\mathrm{P}=0.292: \mathrm{NS}$ \\
\hline Mean onset time of motor block (in $\mathrm{min}$ ) & $17.00 \pm 2.040$ & $16.74 \pm 1.838$ & $P=0.505: N S$ \\
\hline Total duration of sensory block (in h) & $13.93 \pm 0.35$ & $14.002 \pm 0.384$ & $\mathrm{P}=0.344: \mathrm{NS}$ \\
\hline Total duration of motor block (in h) & $12.83 \pm 0.16$ & $12.95 \pm 0.29$ & $P=0.06: N S$ \\
\hline Total durationod peri operative analgesia (in h) & 13.930 .35 & $14.002 \pm 0.384$ & $\mathrm{P}=0.344: \mathrm{NS}$ \\
\hline Total does of rescue analgesic in $24 \mathrm{~h}$ & $1.08 \pm 0.542$ & $1.02 \pm 0.839$ & $\mathrm{P}=0.08: \mathrm{NS}$ \\
\hline
\end{tabular}

Although in both groups, there was no significant difference regarding onset and duration of block, but the patient's and surgeon's satisfaction score was better in both groups over other conventional techniques and local anesthetics and adjuvants. VAS score was used to monitor the patients for postoperative pain. VAS was 0 till $8 \mathrm{~h}$ of the study period then it started increasing in both the groups. Patients demanded the first dose of rescue analgesia at $15^{\text {th }} \mathrm{h}$ as shown in Figure 3 .

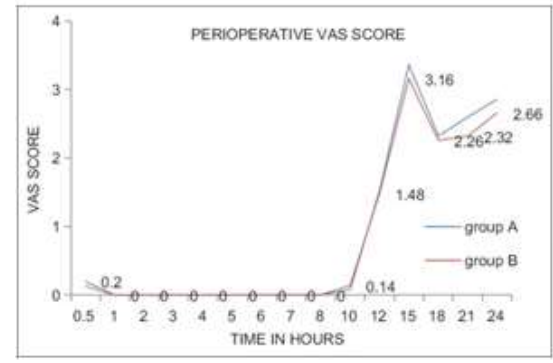

Figure 3: Perioperative visual analogue scale score for $24 \mathrm{~h}$ 


\section{CONCLUSION}

It has been concluded that combined femoral-sciatic nerve block using ropivacaine and fentanyl is one of the most useful yet most neglected anesthetic procedures. This can be used for lower limb surgeries without any major complications and with no drug toxicity. It can be used in critically ill patients where both GA and central coaxial block carries a high risk of mortality. This technique is safe and simple to master and slowly gaining popularity worldwide. It is having minimum hemodynamic instability and can be used in patients with valvular cardiac diseases and other cardiac ailments with fixed cardiac output, diabetic, and even patients on anti-coagulants. Although we could not draw any significant difference by adding fentanyl, but as the technique and drugs used offers prolonged analgesia with negligible toxicity over other traditional techniques and drugs, so overall patient's satisfaction is better. So we highly recommend using femoral-sciatic nerve block using ropivacaine with fentanyl for varieties of lower limb procedures.

\section{REFERENCES}

1. White PF, Kehlet H, Neal JM, Schricker T, Carr DB, Carli F Fast-Track Surgery Study Group. The role of the anesthesiologist in fast-track surgery: From multimodal analgesia to perioperative medical care. Anesth Analg. 2007;104:1380-96.

2. Tantry TP, Kadam D, Shetty P, Bhandary S. Combined femoral and sciatic nerve blocks for lower limb anaesthesia in anticoagulated patients with severe cardiac valvular lesions. Indian J Anaesth. 2010;54:235-8.

3. Mansour A. Femoral nerve block versus spinal anesthesia for lower limb peripheral vascular surgery. AJAIC. 2006;9:1.

4. Malik S, Krishna D, Malik S. Combined psoas compartment and sciatic nerve block for lower limb surgery: An alternative anesthetic option in high-risk geriatric patients. Karnataka Anaesth J. 2015;1:85-8.

5. Moore DC. Sciatic and femoral nerve block. J Am Med Assoc. 1952;150:550-4.

6. Baddoo HK. Sciatic and femoral nerve block. Ghana Med J. 2009;43:24-8.

7. Kuthiala G, Chaudhary G. Ropivacaine: A review of its pharmacology and clinical use. Indian J Anaesth. 2011;55:104-10.

8. Mehourotra MS, Mehourotra MM. Regional block anesthesia - How effective is it for extremity trauma? MJAFI. 2002;58:205-9.

9. Aksoy M, Dostbil A, Ince I, Ahiskalioglu A, Alici HA, Aydin A, et al.. Continuous spinal anaesthesia versus ultrasound-guided combined psoas compartment-sciatic nerve block for hip replacement surgery in elderly high-risk patients: A prospective randomised study. BMC Anesthesiol. 2014;14:99.

10. Akkaya A, Tekelioglu UY, Demirhan A, Ozturan KE, Bayir $\mathrm{H}$, Kocoglu $\mathrm{H}$, et al.. Ultrasound-guided femoral and sciatic nerve blocks combined with sedoanalgesia versus spinal anesthesia in total knee arthroplasty. Korean J Anesthesiol. 2014;67:90-5.

11. Mohan V, Jithendra, Dhanan B, Sugath S. TKR under combined femoral and sciatic nerve blocks. Kerala J Orthop. 2014;27:104-6.

\section{Source of Support: None Declared Conflict of Interest: None Declared}

Policy for Articles with Open Access:

Authors who publish with MedPulse International Journal of Anesthesiology (Print ISSN:2579-0900) (Online ISSN: 2636-4654) agree to the following terms: Authors retain copyright and grant the journal right of first publication with the work simultaneously licensed under a Creative Commons Attribution License that allows others to share the work with an acknowledgement of the work's authorship and initial publication in this journal.

Authors are permitted and encouraged to post links to their work online (e.g., in institutional repositories or on their website) prior to and during the submission process, as it can lead to productive exchanges, as well as earlier and greater citation of published work. 